\title{
Anlaufstelle für geflüchtete Wissenschaftler
}

Enrico Danieli

1 Vergl. Kreft G. Philipp Schwartz (1894-1977): Zürich und die Notgemeinschaft deutscher Wissenschaftler im Ausland -

Schriftreihe der Deutschen Gesellschaft für Geschichte der Nervenheilkunde. Band 18; 2012

Korrespondenz: Dr. med. Enrico Danieli Via ai Colli 22 CH-6648 Minusio Tel. 0917434789 e.b.danieli[at]bluewin.ch
Was geht uns die Vergangenheit an? Macht es Sinn, sich mit dieser zu beschäftigen? Die Vergangenheit, schreibt Christa Wolf, ist nicht tot, sie ist nicht einmal vergangen.

Kennen Sie Philipp Schwartz, den Neuropathologen? Tausende von Menschen konnten dank Philipp Schwartz dem Naziregime entfliehen. Die Aussagen von der als Zeitzeugin lebenden Tochter von Philipp Schwartz, Susan Ferenz-Schwartz, zusammen mit weiteren Dokumenten [1] führen zusammengefasst zu diesen Erkenntnissen:

Philipp Schwartz, 1894 im ungarischen Banat geboren, nahm als Leutnant am Ersten Weltkrieg teil, habilitierte sich danach in Frankfurt am Main und wurde dort zum ausserordentlichen Professor für Pathologie ernannt. Von Kollegen gewarnt, floh er mit seiner vierköpfigen Familie zu den Schwiegereltern nach Zürich. Überwältigt von der grossen Anzahl geflüchteter Wissenschaftler, die er, zur Untätigkeit verdammt, in Zürich traf, entschloss er sich zu handeln. Er rief die Organisation «Zentralberatungsstelle für deutsche Gelehrte» ins Leben. Zweckdienliche Mitteilungen, hiess es, seien an die Plattenstrasse 52 in Zürich zu richten, es ist jenes Haus, in dem sein Schwiegervater eine Privatschule unterhielt (heute wird das stattliche Haus von der Kantonsschule Rämibühl für den Instrumentalunterricht genutzt). Nicht

\section{Er rief die Organisation \\ «Zentralberatungsstelle für \\ deutsche Gelehrte» ins Leben.}

zu vergessen die an Theodor Billroth erinnernde Gedenktafel, der in diesem Haus gewohnt und im Sommer 1866 hier zusammen mit Johannes Brahms musiziert hat. Und leider gilt es hier auch, daran zu erinnern, dass Billroth den deutschen Juden die Eignung zum Deutschtum abgesprochen hat. Es ist eine Ironie des Schicksals, dass es grade in diesem Haus war, in dem Philipp Schwartz zusammen mit Sinai Tschulok, seinem Schwiegervater, Tausende von deutschen Juden rettete.

Zudem setzte sich Philipp Schwartz aktiv für die Vermittlung seiner vielen Kollegen ein, die er zu Hunderten an Universitäten in die Türkei vermittelte. Und nicht nur Mediziner rettete der Neuropathologe vor

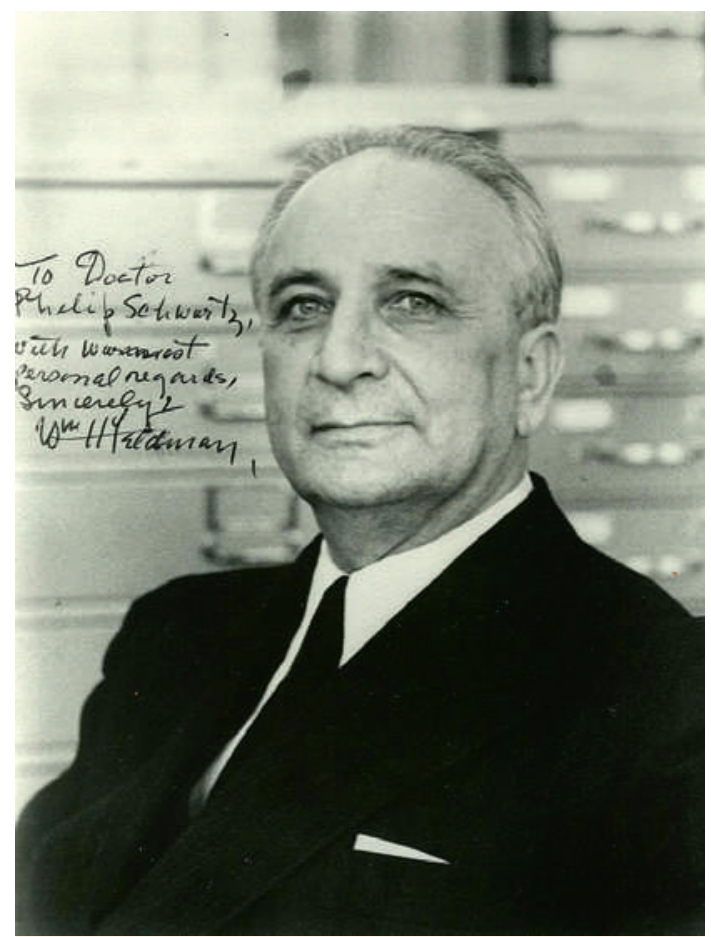

Philipp Schwartz in den 1950er Jahren.

(Quelle: Archiv Gerald Kreft)

dem Naziregime, sondern auch Gelehrte, Künstler, Techniker, Politiker. Weil Philipp Schwartz nach dem Krieg verwehrt worden war, nach Frankfurt zurückzukehren (!), wanderte er 1952 in die USA aus, nachdem er während Jahren das Institut für Pathologie an der Istanbuler Universität geleitet hatte. Dort hatte er auf dem Gebiet des Schlaganfalles, der Tumorpathologie, der Geburtstraumen und des Morbus Alzheimer geforscht. Im Jahr 1977, 83-jährig, stirbt Philipp Schwartz in Florida. Nach seinem Tod wird durch Vermittlung der als Psychiaterin tätigen Tochter Suzan Ferenz-Schwartz die Überführung der Urne von Philipp Schwartz nach Zürich in die Wege geleitet, wo der Neuropathologe auf dem Friedhof Fluntern ganz in der Nähe von James Joyce und Elias Canetti ruht. Im Gegensatz zu den Weltliteraten war das Grab von Philipp Schwartz während Jahrzehnten kaum noch auffindbar, kein Schild wies den Weg zum Ehepaar Schwartz-Tschulok. Doch das hat sich nun endlich geändert: Mit der Einweihung des Ehrengrabes für Philipp Schwartz am 11. April 2014 hat die Stadt Zürich das nachgeholt, was schon seit langer Zeit überfällig war. 